\title{
SOCIAL DEMOGRAPHIC CHARACTERISTICS OF WOMEN WITH PELVIC ORGAN PROLAPSE AT THE TAMALE TEACHING HOSPITAL, GHANA
}

\author{
S.K. GUMANGA, A. MUNKAILA and H. MALECHI \\ University for Development Studies, School of Medicine and Health Sciences, Department of Obstetrics \& \\ Gynaecology, Tamale Teaching Hospital, Tamale, Ghana.
}

DOI: $h t t p: / / d x . d o i . o r g / 10.4314 / g m j . v 48 i 4.7$

Corresponding Author: Dr Solomon K Gumanga

Email address: gumangask@yahoo.co.uk

Conflict of interest: None declared

\section{SUMMARY}

Objective: To determine the prevalence, social demographic characteristics and types of pelvic organ prolapse that patients present with at the Tamale Teaching Hospital (TTH).

Methods: A descriptive study of pelvic organ prolapses at the Tamale Teaching Hospital from $1^{\text {st }}$ January 2010 to $31^{\text {st }}$ December 2011.

Results: The 118 pelvic organ prolapse cases constituted $(2.68 \%)$ of the 4403 gynaecological out-patient cases seen during the two year study period. The mean age and standard deviation was $(45.9 \pm 15.1)$ and the modal age group was $30-39$ years with 32 (27.1\%) of cases. There were $112(94.9 \%)$ cases of uterine prolapse, $95(80.5 \%)$ had cystocele, $16(13.5 \%)$ patients had rectoceles and $3(2.5 \%)$ had enterocele.

Their main occupations were trading $66(55.9 \%)$ and farming $44(37.3 \%)$, seventy $(62.5 \%)$ of the patients with uterine prolapse were premenopausal while (10) $14.3 \%$ of the premenopausal cases had an ongoing pregnancy. The parity ranged from zero to 13 with mean and standard deviation of $(4.4 \pm 1.7)$. Fifty five $(46.6 \%)$ were from the Tamale metropolis and only 12 $(10.5 \%)$ had all their deliveries in hospital.

The commonest complication was decubitus ulcer present in $20(16.9 \%)$ patients, $16(80 \%)$ of it in patients with procedentia.

Conclusion: Pelvic organ prolapse is not a rare gynaecological condition at the Tamale Teaching Hospital. The patients are relatively young and are from various districts in the northern region. Some occupational, socio-cultural practices and reproductive characteristics may be contributory to severity of pelvic organ prolapse.

Keywords: Pelvic organ prolapse, uterine prolapse, Tamale Teaching Hospital, Social demographic characteristics.

\section{INTRODUCTION}

Pelvic organ prolapse is an anatomic support defect of the pelvic viscera. It may result from a series of long term failure of the supporting and suspension mechanisms of the uterus and vaginal wall. ${ }^{1}$ The defect in the support structures results in downward displacement of structures that are normally located adjacent to the vaginal vault. ${ }^{2}$ Damage to the support structures begins in first vaginal delivery ${ }^{2}$, subsequent deliveries will contribute to prolapse due to the force of labour, maternal bearing down efforts, fundal pressure application and traction by attendants, both skilled and unskilled causing damage to pelvic floor and its support structures. ${ }^{2}$

Prolonged labour at home before going to a health facility or conduct of labour by unskilled attendants causes significant damage to the pelvic support system. Outside the reproductive years, advancing age and resultant weakness in pelvic floor muscles occurs during the menopause and can lead to pelvic organ prolapse.,

${ }^{3}$ This is as a result of atrophy of pelvic tissues due to hypo estrogenic state.

Some progress has been made in recent years to improve patronage of skilled delivery services and contraceptive services to reduce morbidity and mortality associated with child birth in Ghana however many women in the northern region of Ghana deliver not within health facilities and are yet to accept fertility control. Only $27.2 \%$ of pregnant women in the northern region had supervised delivery by skilled provider while majority of the delivery; $55.5 \%$ of women were delivered by a TBA and about $17 \%$ were delivered by a relative or no one in the region. ${ }^{4}$ All these unskilled delivery have resultant adverse effect on pelvic floor anatomy. 
In areas of high parity with little or no access to health care, countless number of women suffers from problems associated with pelvic organ prolapse with no real possibility of resolution ${ }^{2}$; this is the situation in Northern Ghana. Damage caused by childbirth and increasing parity, big baby, premature bearing down in labour and operative vaginal delivery with other factors such as aging and menopause, work together over time and predispose women to pelvic organ prolapse.

Some activities related to lifestyle or disease in these women could precipitate or promote the process of pelvic organ prolapse. Lifestyle such as heavy weight lifting as a result of trading, farming, carrying firewood, water or even the many babies delivered and chronic cough due to tuberculosis, bronchitis or asthma. Other diseases include chronic constipation, ascites, intra-abdominal masses. Any condition that increases pressure in the abdomen and affect the physical load on the pelvic floor or integrity of the muscular and connective tissues of the pelvis increases the likelihood that symptomatic prolapsed will develop. ${ }^{5}$

A study of pelvic organ prolapse done in a rural community in southern Ghana shows a prevalence rate of $12.07 \%{ }^{6}$ however the exact burden of pelvic organ prolapses across the entire country is unknown. The prevalence of pelvic organ prolapse in northern and southern parts of Ghana particularly the urban areas are not expected to be same because of differences in occupational, socio-cultural factors, access and use of health facilities between the two parts of the country. ${ }^{4}$

Pelvic organ prolapse negatively affects socioeconomic and reproductive activity of affected women; it is therefore of interest to study the condition and the affected women from all over the northern region presenting to the Tamale Teaching hospital. The main objective of this study was to determine the prevalence, social demographic characteristics and types of pelvic organ prolapse seen at the Tamale Teaching hospital during the two year study period. Some recommendations could be made which may positively modify behavior and practice.

\section{SUBJECTS AND METHODS}

This is a descriptive study of pelvic organ prolapse (POP) at the Tamale Teaching Hospital in the Northern Region of Ghana from $1^{\text {st }}$ January 2010 to $31^{\text {st }}$ December 2011. The needed data were collected using a form designed to capture the social demographic characteristics, reproductive history and pelvic examination findings of patients with pelvic organ prolapse seen at the Obstetrics and Gynaecology department of the Hospital during the study period.
After explaining the objective of the study, the questionnaires were translated to the patients mainly in a local language to their understanding. Members of the research team made up of doctors and nurses daily during clinic visits and at the time of admission to the gynaecology ward administered the questionnaires.

Difficulties with retrieval of folders for retrospective studies and incomplete data entries in the manual system of keeping information on patients were not encountered. Confirmation and reconciliation of some of the data were done using records from the Gynaecology clinic, the major surgical log book in the operating theatre and the wards.

The patients included in this study were either referred from other health facilities in the region or they presented to the department of obstetrics and gynaecology of Tamale Teaching Hospital with complaints associated with pelvic organ prolapse. The main complaints included "a mass falling from the vagina" or "bulging mass" or "sensation of mass in the vagina". Those with these complaints found with demonstrable descent of any pelvic organ during pelvic examination were included.

The pelvic organ prolapse findings were obtained by examining the patients in dorsal lithotomy position or left lateral position. With the aid of Sim's speculum the apical, anterior and posterior vaginal wall defects as well as the perineum was assessed at rest and with Valsalva manoeuvre.

The type and severity of any pelvic organ prolapse were determined and classified using the Beechem and Bump classification and grading system of vaginal relaxation. ${ }^{7,8}$ This old system of classification of prolapse into mild, moderate, severe or stages I, II and III was used because it is simpler, less expensive and allowed junior doctors who are used to this system of classification to be part of the data collection.

This method however has some limitations in accurately describing pelvic organ prolapse. Two modern systems: the Baden Walker Halfway System and Pelvic Organ Prolapse Quantification (POP-Q) are currently being encouraged for use because they are complete in the examinations and more informative on the anatomic defects ${ }^{2}$.

The POP-Q system is more comprehensive classification with good inter-observer and intraobserver reliability of physical examination findings. ${ }^{2,5}$ 
Patients with non-puerperal uterine inversions, prolapsed fibroid polyps and those with complaints but with no demonstrable descent of any pelvic organ following pelvic examination were excluded from the study.

The data collected on the patients included in the study were coded and entered into Statistical Package for Social Sciences (SPSS, Chicago Inc) version 16.0 for windows. Statistical analysis were done and the needed information transferred into tables created with the desired columns and rows labeled with the needed variable. The data presented in the tables are frequency distributions. Statistical significance at a p-value $<0.05$ were determined at $95 \%$ confidence interval using ANOVA and Pearson's correlation coefficient (r).

\section{RESULTS}

A total of 118 cases of pelvic organ prolapse 46 in 2010 and 72 in 2011 were seen during the two year study period, an average of one new case of pelvic organ prolapse reported to the hospital per week. Their ages ranged from 18-78 years with a mean age of 45.9years and standard deviation of 15.1years.

Pelvic organ prolapse cases constituted $2.68 \%$ of the 4403 gynecological out-patient cases seen at the department of Obstetrics and Gynaecology of the Tamale Teaching Hospital during the study period. Table 1 shows the distribution of age and parity of the 118 patients with pelvic organ prolapse in this study.

Table 1 Age and parity distribution of patients with pelvic organ prolapse seen at the TTH 2010-2011.

\begin{tabular}{|l|l|l|l|l|}
\hline \multicolumn{2}{|c|}{ Variable } & Frequency & $\begin{array}{l}\text { Percent } \\
(\%)\end{array}$ & Mean, SD \\
\hline \multirow{6}{*}{ Age } & $<20$ & 1 & 0.8 & \\
(years) & $20-29$ & 16 & 13.6 & \\
& $30-39$ & 32 & 27.1 & \\
& $40-49$ & 19 & 16.1 & $45.9,15.1$ \\
& $50-59$ & 19 & 16.1 & \\
& $60-69$ & 15 & 12.7 & \\
& $70-79$ & 16 & 13.6 & \\
\cline { 2 - 5 } & Total & 118 & $100 \%$ & \\
\hline \multirow{5}{*}{ Parity } & 0 & 4 & 3.4 & \\
& $1-2$ & 17 & 14.4 & \\
& $3-4$ & 32 & 27.1 & \multirow{6}{*}{} \\
& $5-6$ & 29 & 24.6 & $4.4,1.7$ \\
& $7-8$ & 24 & 20.3 & \\
& $9-10$ & 9 & 7.6 & \\
& $11+$ & 3 & 2.5 & \\
\cline { 2 - 5 } & Total & 118 & $100 \%$ & \\
\hline
\end{tabular}

The modal age group with pelvic organ prolapse was $30-39$ years making $27.1 \%$ of the cases. Women older than 40years had more severe prolapse.
One hundred and ten (93.2\%) had all their deliveries vaginally, four $(3.4 \%)$ had history of one previous caesarean section and another four $(3.4 \%)$ were nulliparous.

The mean parity was 4.4 with just one in eight of these women having had a delivery in hospital. One nulliparous woman less than twenty years had a third degree uterine prolapse without cystocele.

Fifty-five (46.6\%) of the cases of pelvic organ prolapse were from the Tamale metropolis and the rest were referrals from towns in other districts of the northern region. They were predominantly from the main ethic group of these towns and districts and their main occupations were trading $66(55.9 \%)$ and farming 44 $(37.3 \%)$ and delivered most of their babies outside health facilities. Fifty one $(44.7 \%)$ of the women who had delivered had indicated previous use of herbal utero-tonics; a common traditional practice during labour by some ethnic groups. Table 2 shows details of some social-demographic characteristics of the patients with pelvic organ prolapse in this study.

Table 2 Social demographic characteristics of patients with pelvic organ prolapse seen at TTH 2010-2011.

\begin{tabular}{|c|c|c|c|}
\hline \multicolumn{2}{|l|}{ Variable } & \multirow{2}{*}{$\begin{array}{l}\text { Frequency } \\
44 \\
66 \\
8\end{array}$} & \multirow{2}{*}{$\begin{array}{l}\begin{array}{l}\text { Percent } \\
(\%)\end{array} \\
37.3 \\
55.9 \\
6.8 \\
\end{array}$} \\
\hline Occupation & $\begin{array}{l}\text { Farmers } \\
\text { Traders } \\
\text { Others }\end{array}$ & & \\
\hline & Total & 118 & 100 \\
\hline \multirow[t]{2}{*}{ Town } & $\begin{array}{l}\text { Tamale } \\
\text { Yendi } \\
\text { Savulegu } \\
\text { Salaga } \\
\text { Damango } \\
\text { Bimbilla } \\
\text { Tolon-Kunbugu } \\
\text { Others } \\
\end{array}$ & $\begin{array}{l}55 \\
10 \\
9 \\
6 \\
9 \\
4 \\
5 \\
20 \\
\end{array}$ & $\begin{array}{l}46.6 \\
8.5 \\
7.6 \\
5.1 \\
7.6 \\
3.4 \\
4.2 \\
17.0 \\
\end{array}$ \\
\hline & Total & 118 & 100 \\
\hline \multirow[t]{2}{*}{$\begin{array}{l}\text { Place of previous } \\
\text { deliveries }\end{array}$} & $\begin{array}{l}\text { Home } \\
\text { TBA } \\
\text { Hospital } \\
\text { Home \& TBA } \\
\text { Home \& MH } \\
\text { Home\& Hospital } \\
\text { Home, TBA } \\
\text { \& Hospital } \\
\end{array}$ & $\begin{array}{c}65 \\
10 \\
12 \\
9 \\
3 \\
1 \\
14\end{array}$ & $\begin{array}{l}57.0 \\
8.8 \\
10.5 \\
7.9 \\
2.6 \\
0.8 \\
12.5\end{array}$ \\
\hline & Total & 114 & $100 \%$ \\
\hline \multirow{2}{*}{$\begin{array}{l}\text { Use of Herbal } \\
\text { Utero-tonic }\end{array}$} & $\begin{array}{l}\text { Yes } \\
\text { No }\end{array}$ & $\begin{array}{l}51 \\
63\end{array}$ & $\begin{array}{l}44.7 \\
55.3\end{array}$ \\
\hline & Total & 114 & $100 \%$ \\
\hline
\end{tabular}

Ninety-five $(80.5 \%)$ of the patients with pelvic organ prolapse had the condition for at least one year, with uterine prolapse and cystocele being main organs involved. 
Seventy $(62.5 \%)$ of the patients with uterine prolapse were premenopausal while (10) $14.3 \%$ of the premenopausal cases had an ongoing pregnancy and 29 (41.4\%) noticed their prolapse during the puerperium. Table 3 shows the duration, time of onset and degree of severity of uterine prolapse in $112(94.9 \%)$ of the patients who presented with pelvic organ prolapse. There were $95(80.5 \%)$ cystoceles of which seven were presenting without uterine prolapse with five in premenopausal women.

Table 3 Cross tabulation of duration and time of onset on severity of uterine prolapse seen at the TTH 2010-2011.

\begin{tabular}{|c|c|c|c|c|c|}
\hline \multirow{2}{*}{ Duration of prolapse } & \multirow{2}{*}{ Time of Onset } & \multicolumn{4}{|c|}{ Degree of uterine prolapse } \\
\hline & & First degree & Second degree & $\begin{array}{l}\text { Third degree } \\
\text { (Procedentia) }\end{array}$ & Total \\
\hline \multirow[t]{2}{*}{ Less than a year } & Premenopausal & 5 & 10 & 4 & $19(16.9 \%)$ \\
\hline & Postmenopausal & 0 & 1 & 3 & $4(3.6 \%)$ \\
\hline \multirow[t]{2}{*}{$1-3$ years } & Premenopausal & 7 & 9 & 13 & $29(25.9 \%)$ \\
\hline & Postmenopausal & 5 & 3 & 7 & $15(13.4 \%)$ \\
\hline \multirow[t]{2}{*}{$3-5$ years } & Premenopausal & 2 & 1 & 4 & $7(6.2 \%)$ \\
\hline & Postmenopausal & 0 & 2 & 5 & $7(6.2 \%)$ \\
\hline \multirow[t]{2}{*}{ Over 5 years } & Premenopausal & 2 & 4 & 9 & $15(13.4 \%)$ \\
\hline & Postmenopausal & 3 & 2 & 11 & $16(14.3 \%)$ \\
\hline \multicolumn{2}{|l|}{ Total } & $24(21.4 \%)$ & $32(28.6 \%)$ & $56(50.0 \%)$ & $112(100 \%)$ \\
\hline
\end{tabular}

Six $(5.1 \%)$ of the patients had pelvic organ prolapse not involving the bladder and the uterus. Sixteen $(13.5 \%)$ of the patients had rectocele, $3(2.5 \%)$ had enterocele. Figure 1 is the graph of degrees of severity of cystocele occurring with various degrees of severity of uterine prolapse.

Figure 1 Severity of cystocele occurring with various degrees of uterine prolapse in 113 patients with pelvic organ prolapse at the TTH 2010-2011.

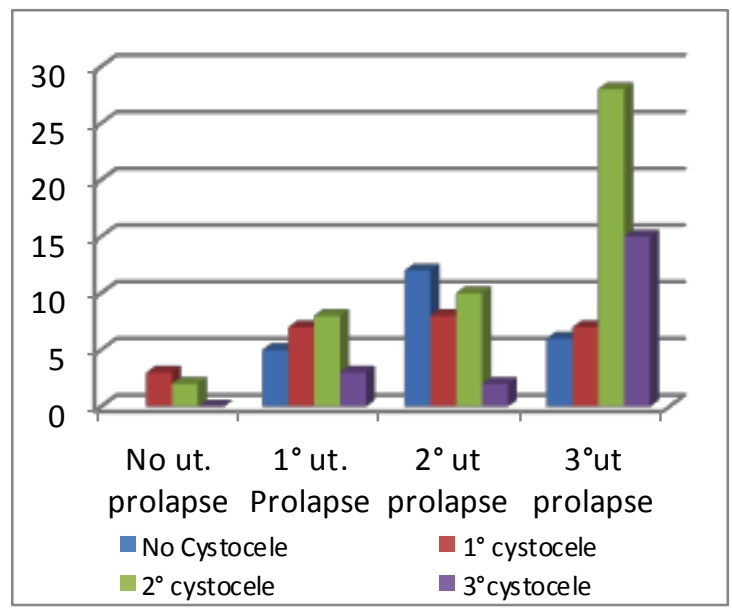

There was weak correlation between the severity of uterine prolapse and severity of associated cystocele, $\mathrm{r}=.276, \mathrm{p}=.014$ at $95 \%$ interval. Using ANOVA, the degree of severity of uterine prolapse and the degree of severity of cystocele were found to be dependent $\mathrm{p}=0.009$
Twenty patients (16.9\%) had decubitus ulcer which was the commonest complication; $16(80 \%)$ of the decubitus ulcer was in patients with procedentia; giving a rate of $28.6 \%$ decubitus ulcer in patients with procedentia. Other complications included urinary retention

$7(5.9 \%)$, urinary incontinence $4(3.3 \%)$, gapping perineum $15(12.7 \%)$ and $2(1.7 \%)$ patients had damaged anal sphincter with faecal incontinence.

The patients described in this review were managed conservatively and surgically taking into consideration their ages, reproductive wishes and severity of the condition and associated complications.

\section{DISCUSSION}

Pelvic organ prolapse is not a rare gynaecological condition at the Tamale Teaching Hospital as shown in this hospital based study of 118 patients who presented with complaints of prolapse or symptoms associated with it. Several women with lesser degree of prolapse with no severe symptoms may not visit any health facility; hence the condition may not be recognized.

A recent study done in a rural community in the southern part of Ghana found the prevalence of pelvic organ prolapse to be $12.07 \%{ }^{6}$ In this hospital based study of pelvic organ prolapse in the northern region of Ghana, the prevalence of $2.68 \%$ seen in the out-patients population during the two year study may be an indication that more women suffer from this condition in the community. 
Pelvic organ prolapse is not a life threatening condition it however affects negatively the quality of life of women with any degree of prolapse.

Those affected by this morbid condition in the remote areas may be silent about the disease until their symptoms are severe enough to compel them to visit hospital for medical treatment. They would usually not complain or talk about this because of the shame and sigma that is associated with disease involving the genital organs in the rural areas.

Lifestyle and occupational activities that involve straining or lifting objects heavy enough to require Valsalva maneuver or fixation of the respiratory diaphragm displaces stress directly down on the pelvic floor contributing to pelvic organ prolapse. ${ }^{2,9}$ In this study $62.5 \%$ of the patients were premenopausal, leaving the predominant occupations of trading and farming, and their parity as factors probably responsible for the pelvic organ prolapse as seen in other studies done in parts of west Africa where over $60 \%$ of premenopausal women had pelvic organ prolapse supporting the role of parity and physical activity. $6,10,11$

Many rural women engage in daily lifting or carriage of water, farm produce, fire wood, and traded goods. These activities increases risk for pelvic organ prolapse or worsen existing weakness. These activities ensure economic survival so any life style changes that are necessary for successful management are difficult to implement. Studies done in European populations however showed women presented mostly in their menopause with pelvic organ prolapse with childbirth playing much role. Thus pelvic floor damage associated with childbirth and not just the menopausal state were the main factors leading to pelvic organ prolapse. $^{3,9}$ In this study, $14.3 \%$ of premenopausal women presented with pelvic organ prolapse with an ongoing pregnancy, a situation which may be associated with worsening symptoms of the disease, increased pregnancy loss and preterm delivery.

Parturition and increasing parity is associated with pelvic floor damage ${ }^{2,9}$ even if it is attended to skilled labour attendants. The mean parity of women in this study was 4.4 with many of the deliveries not within health facilities; the high mean party is consistent with mean parities in other studies. ${ }^{6,10,11}$ Prolonged and difficult labour at home and even sometimes within health facilities all contribute significantly to pelvic floor damage even during the first parturition. Harmful conduct of labour by unskilled attendants such as application of fundal pressure, premature bearing down, use of herbal uterotonic, wrong technique in delivery of the placenta all have a combined effect resulting in pelvic floor damage and pelvic organ prolapse in the long term.

Uterine prolapse and cystocele were the commonest pelvic organs in this study; prolapse of these organs is related to apical and anterior vaginal wall defects and were of variable severity. Only one in five of these women with pelvic organ prolapse reported to the hospital within a year of onset of the disease. They probably had to travel from a far place before reaching the hospital, lack financial resources or they are caught up in a shame, sigma, silence cycle until their social and economic life is adversely and severely affected by their illness. The prolonged delay in coming to hospital resulted in complications and increased morbidity such as decubitus ulcer present in $16.9 \%$, difficulty with defecation, urinary retention, increased discomfort associated with the prolapse, sexual dysfunction leading to marital disharmony and reduction in economic and social activity.

In this study, four (3.4\%) of the women with Pelvic organ prolapse were nulliparous, one 18 year old nullipara presented with procedentia. Such severe degree of prolapse at a very young age without any identifiable risk factor may be due to constitutional connective tissue disorders such as 'Ehlers-Danlos Syndrome' which is characterized by fascial and connective tissue weakness ${ }^{2}$ a rear condition in which management could be challenging if the patients coital and reproductive desires are to be met.

\section{CONCLUSION}

Pelvic organ prolapse is not a rare gynaecological condition at the Tamale Teaching Hospital. The patients are relatively young and are from various districts in the region. Some occupational, socio-cultural practices and reproductive characteristics may be contributory to severity of pelvic organ prolapse.

\section{LIMITATION}

This is a hospital-based study amongst women presenting with symptoms of pelvic organ prolapse, there is the need for population study to determine the prevalence of pelvic organ prolapse in Ghana. Despite the simple grading system used in this study, there is still a possibility of observer dependent variability in the grading of pelvic organ prolapse since the examination of the patients was not done by one researcher. 


\section{RECOMMENDATION}

Life style modifications, mechanized farming, and use of alternative means to convey farm produce and traded items with active involvement of males will go a long way to reduce pelvic organ prolapse. Surgical services for affected patients could be provided in hospitals within the various communities if there is an increase in the number of gynecologist in the northern region of Ghana.

\section{ACKNOWLEDGEMENT}

Sincere gratitude to Dr. Isaac Aboagye Marfo, Ms. Millicent Kumassey, Hajia Amira Iddrisu and Ms. Amina Abu all of the Department of Obstetrics and Gynaecology, Tamale Teaching Hospital and all others who contributed in putting this paper together.

\section{REFERENCES}

1. Gin-Den C, Soo-Cheen NG. Updated Definition of Female Pelvic Organ Prolapse. Incont Pelvic Floor Dysfunct 2007; 1(4): 121-124.

2. Zimmerman $\mathrm{C}$ W. Pelvic organ prolapse. In: Rock JA, Jones HW, editors. Te Linde's operative gynecology 9th edition. Lippincott Williams \& Wilkins. 2008; 354-360.

3. Mant J, Painter R, Vessey M. Epidemiology of genital prolapsed. Observations from the Oxford Family Planning Association Study. $\mathrm{Br} \mathrm{J}$ Obstet Gynaecol 1997; 104:579- 585.
4. Ghana demographic and health survey 2008. http://www.measuredhs.com/pubs/pdf/FR221/FR2 21.pdf. Accessed in December 2011.

5. Hall AF, Theofrastous JP, Cundiff GW et al. Interobserver and intra-observer reliability of the proposed international continence society, society of Gynaecologic surgeons and American Urogynecologic Society pelvic organ prolapse classification system. Am J Obtet Gynecol 1996; 175: 1467-1471.

6. Wusu-Ansah OK, Opare-Addo HS. Pelvic organ prolapse in rural Ghana. International Journal of Obstetrics and gynecology, 2008; 103: 121-24

7. Beechem CT: Classification of vaginal relaxation. Am J. Obstet and Gynecol, 1980; 957-958.

8. Bump RC, Mattiason A, Bok et al. The standardization of terminology of female pelvic floor dysfunction. Am J Obstet Gynaecology 1996; 175: 10-17.

9. DeLancey JOL. Anatomy and biomechanics of genital prolapse. Clin Obstet Gynecol. 1993; 36:897-909.

10. Scherf C, Morison L, Fiander A, Ekpo G, Walraven G. Epidemiology of pelvic organ prolapse in rural Gambia, West Africa. Br J Obstet Gynaecol, 2002; 109: 431-436.

11. Menur A, Hailemariam S. Pelvic organ prolapse in Jimma University Specialized Hospital, Southwest Ethiopia. Ethiop J Health Sci. 2012; 22: (2): 8592. $\bullet$ 